\title{
GESTÃO ESCOLAR E ADMINISTRAÇÃO EMPRESARIAL: APROXIMAÇÃO E CONFRONTO
}

\author{
Adriana de Lanna Malta Tredezini* \\ Jefferson Idelfonso da Silva*
}

\begin{abstract}
RESUMO
Estas reflexões pretendem analisar em que teorias se baseia a gestão administrativa no ensino superior, bem como confrontá-las com as teorias administrativas atuais, verificando se há articulação entre o universo administrativo e o universo pedagógico na escola e a partir daí tentar contribuir com uma nova alternativa para a gestão escolar. A estrutura organizacional burocrática da escola tem se mostrado desarticulada do processo pedagógico e ineficiente nas questões administrativas, não contribuindo para a melhoria de qualidade nos aspectos pedagógicos. $\mathrm{O}$ caminho proposto para superar esse problema é buscar nas teorias organizacionais modernas as diretrizes para a gestão escolar, ainda que seja necessário afrontar o desafio de salvaguardar a especificidade pedagógica da escola e assumir sem preconceitos os fundamentos organizacionais das administrações atuais. Foram consideradas a Administração Participativa, a Administração Holística e, principalmente, a Administração Estratégica como possíveis formas de administração capazes de garantir a qualidade da educação.
\end{abstract}

Palavras-chave: Gestão escolar. Teorias de Administração. Qualidade da Educação.

* Mestre em Educação pelo Centro Universitário do Triângulo - UNITRI.

** Doutor em Educação pela Universidade Católica de São Paulo. 


\begin{abstract}
The intention of these reflections is to analyze which theories administrative management of higher education is based on, as well as to compare them with current administrative theories in order to corroborate if there is articulation between the administrative universe and the pedagogical universe in the school. Based on this is an attempt to contribute with a new alternative for school management. The bureaucratic structural organization of the school has proven to be disarticulated from the pedagogical process and inefficient in administrative questions, not contributing to the improvement in the quality of pedagogical aspects. The way proposed to overcome this problem is to discover directives for school management in modern organizational theories, even if it may be necessary to face the challenge of safeguarding the pedagogical specificity of the school and take on the organizational basis of current administrations without preconceptions. Participative Administration, Holistic Administration and, principally, Strategic Administration were considered possible forms of administration capable of guaranteeing the quality of education.
\end{abstract}

Keywords: School management. Administrative theories. Quality of education.

\title{
Introdução
}

Estas reflexões pretendem analisar em que teorias se baseiam a gestão administrativa no ensino superior, bem como confrontálas com as teorias administrativas atuais, verificando se há articulação entre o universo administrativo e o universo pedagógico na escola e a partir daí tentar contribuir com uma nova alternativa para a gestão escolar.

A estrutura organizacional burocrática da escola tem se mostrado desarticulada do processo pedagógico e ineficiente nas questões administrativas. A prática dos diretores tem legitimado

Educ. e Filos., Uberlândia, v. 20, n. 39, p. 163-185, jan./jun. 2006. 
essa estrutura organizacional burocrática e não tem contribuído para a melhoria de qualidade nos aspectos pedagógicos.

O caráter cartorial e burocrático da escola afeta profundamente sua administração. Aliás, há na escola uma grande desarticulação entre o universo pedagógico e o universo administrativo, o que causa prejuízo ao processo educacional. Uma administração burocrática está sujeita à hierarquia e ao regulamento rígidos e à uma rotina inflexível. Segundo Rezende (1987, p. 23), no próprio processo de modernização da universidade brasileira a burocratização teve um papel importante, enquanto nessa época, "modernizar significou burocratizar, e burocratizar significou multiplicar e 'reformar' as leis relativas ao ensino, à estrutura e ao funcionamento de nossas universidades." Entretanto, a burocracia não pode e não deve ser a mola propulsora da administração. É Rezende ainda (1987, p.82) que alerta para os problemas de uma administração burocrática:

O aparelho burocrático mecanicamente montado tende a fortalecer a centralização, a tal ponto que o conjunto de decisões relevantes fique nas mãos de uma ou de algumas pessoas apenas. Nesse sentido, a burocracia significa exatamente a diluição da autoridade e da responsabilidade, numa evidente despersonalização dos funcionários. (p.39). [...] a burocracia, principalmente quando racionalizada e mecanizada, aparece como exercício de um poder que controla e manipula os meios em detrimento dos fins. (p. 50). [...] Enquanto o funcionalismo americano sugere que a administração é o lugar onde se fabrica o consenso, Weber insiste na burocracia como dominação: administrar é "vigiar e punir" (FOUCAULT).

Ao relacionar a escola com a empresa, constata-se que ela se distancia da empresa ao não se utilizar dos progressos gerenciais desenvolvidos por esta para se modernizar. Parece, e tentaremos averiguar, que falta uma fundamentação que norteie e estabeleça princípios para a gestão escolar. 
Aos poucos, compreendi que o setor de negócios é o lugar certo para inovações numa sociedade aberta, pois nele existe a liberdade de experimentar que falta ao setor público e às organizações não lucrativas (SENGE, 1990, p. 24).

Nos dias atuais, é imperativo que a educação esteja inserida na era da administração moderna. Entretanto, ao se fazer uma primeira e superficial análise do comportamento da administração escolar, pode-se constatar que os gestores do ensino superior, mesmo em instituições que ministram cursos de Administração, parecem não fazer uso das ferramentas já aplicadas e testadas pela empresa em seu processo gestionário. A administração das Instituições de Ensino Superior (IES) mostra-se aquém daquilo que poderia ser, em eficiência e qualidade. A organização e a gestão escolar são os meios com os quais a escola busca atingir seu objetivo genuíno que é o processo de ensino e aprendizagem. Mas, mesmo não sendo uma atividade final, a administração escolar é de suma importância para que o objetivo maior da escola possa ser atingido.

As tarefas da administração escolar compreendem os atos de gerir, organizar, dirigir, tomar decisões, entre outras, e são semelhantes às tarefas da administração empresarial.

A gestão, na verdade, é o meio para viabilizar objetivos. Quando uma organização quer alcançar resultados ousados, é preciso planejar, definir os fins a serem atingidos, distribuir responsabilidades, executar o que foi projetado e, finalmente, avaliar, comparando o que foi planejado com os resultados obtidos (MARCOVITCH, 1998, p. 151).

Segundo Paro (1986), "a administração é a utilização racional de recursos para a realização de fins determinados". Por utilização racional de recursos entende-se que estes recursos estejam adequados aos fins visados e que sejam geridos de forma econômica. Isso vale tanto para a empresa quanto para a instituição de ensino.

Os princípios adotados pela administração escolar vêm dos fundamentos da educação (da filosofia da educação, da sociologia

Educ. e Filos., Uberlândia, v. 20, n. 39, p. 163-185, jan./jun. 2006. 
da educação, da psicologia da educação e outros) e não do que se poderia chamar de uma teoria própria da administração escolar. Segundo Estrela (1992), a Pedagogia não possui um estatuto científico próprio: é uma ciência que ainda está se constituindo e, por isso, ela mesma se fundamenta em outras ciências tentando explicar-se.

A necessidade de cientificação tem levado o interventor pedagógico a recorrer a conceitos e a métodos de ciências já constituídas, que poderão ter aplicação no seu campo específico - o da educação. A Psicologia, a Psicanálise, a Sociologia, a Psicossociologia, a Economia têm representado as principais ciências de recurso (ESTRELA, 1992, p. 12).

Na tentativa de explicitar uma teoria da administração escolar, o que se encontrou, na verdade, foi uma teoria da administração aplicada na empresa que ora é transposta para o âmbito da escola sem uma reflexão crítica ou uma análise das diferenças e semelhanças entre a empresa e a escola; ora é execrada como um mal que não pode atingir a escola.

O estudo da escola como organização de trabalho não é novo, há toda uma pesquisa sobre administração escolar que remonta aos pioneiros da educação nova, nos anos 30. Esses estudos se deram no âmbito da Administração Escolar e, freqüentemente, estiveram marcados por uma concepção burocrática, funcionalista, aproximando a organização escolar da organização empresarial (LIBÂNEO, 2000, p. 69).

Enquanto a Administração de Empresa desenvolve as teorias sobre a organização do trabalho nas empresas capitalistas, a Administração Escolar apresenta proposições teóricas sobre a organização do trabalho na escola e no sistema escolar. No entanto, a Administração Escolar não construiu um corpo teórico próprio e no seu conteúdo podem ser identificadas as diferentes escolas da Administração de Empresa o que significa uma aplicação dessas teorias a uma atividade específica, neste caso, à educação. [...] Os teóricos da 
Administração Escolar procuram utilizar nos seus estudos as teorias da Administração de Empresa, procurando alcançar um grau de "cientificidade" necessário para comprovar a importância da Administração Escolar como orientação teórica capaz de assegurar o funcionamento satisfatório da organização escolar em correspondência às expectativas da sociedade (FÉLIX, 1984, p. 71 e 72).

Isso não significa que as instituições de ensino não podem se valer da teoria da Administração Empresarial. Ao contrário, os estudos sobre gestão, desde que avaliados criticamente e levando em consideração as especificidades da organização escolar, podem contribuir para que a Administração Escolar acompanhe com maior rapidez e flexibilidade o desenvolvimento das organizações dentro de um mundo globalizado.

Por outro lado, não obstante seus componentes autoritários, a atual teoria e prática da administração possui importantes qualidades técnicas que, embora estejam hoje sendo utilizadas em favor dos interesses da classe dominante, podem, nas mãos da classe trabalhadora, articular-se com os interesses dessa classe. A este respeito, não há por que não aproveitar, da administração existente hoje, aqueles componentes que, sem comprometer os objetivos democráticos e de emancipação das classes dominadas, representem um avanço técnico capaz de auxiliar o homem na consecução de seus propósitos (PARO, 1986, p. 78).

Mas é necessário que não se perca de vista aqueles objetivos que são próprios das instituições de ensino. É muito comum, na educação, que se transponha para a escola, sem nenhuma reelaboração crítica, todos os modismos que surgem na Administração Empresarial ou em qualquer outra instância organizacional.

Há, sem dúvida, um transplante acrítico para a administração da Educação dos postulados da Teoria Geral da

Educ. e Filos., Uberlândia, v. 20, n. 39, p. 163-185, jan./jun. 2006. 
Administração. Foi visível esse fato na década de 60 através dos teóricos funcionalistas que trataram da administração da Educação. Quase todos eles seguiram uma linha que toma como equivalente o processo de produção de mercadoria, o processo de produção pedagógica e a administração em geral enquanto uma atividade exclusivamente técnica. A administração escolar não pode ser vista fora do contexto global, isto é, não pode ser isolada da sua realidade, de onde se situa. Caso contrário, procede-se de forma abstrata e nunca se alcançará os objetivos para os quais a escola existe (BARROS, 1998, p. 139).

\section{Problemas macroambientais}

Takeshy e Andrade (1999) apontam alguns problemas macroambientais que afetam especificamente as instituições de Ensino Superior. Percebe-se neles, quando analisam as variáveis que influenciam o macroambiente ou o contexto em que as instituições estão inseridas, o olhar do administrador empresarial, mas preocupados com o objetivo último da instituição de ensino que é o ensino-aprendizagem.

O primeiro deles é a variável ambiental econômica como mudança cambial, taxa de juro, política de concessão de crédito, ou seja, políticas econômicas manipuladas pelo governo. O estado atual da atividade econômica do país atinge diretamente a fixação do valor da mensalidade nas instituições de ensino que serão analisadas e explica o crescimento da inadimplência. O empobrecimento do país e, conseqüentemente da população, faz com que não se tenham recursos para investir nas universidades públicas e dificulta o pagamento das mensalidades nas instituições privadas. A própria política econômica do país não prioriza a educação.

O segundo é a variável ambiental legal, como medidas provisórias sobre mensalidades escolares e a própria Lei de Diretrizes e Bases (LDB), que afeta a elaboração e execução do projeto pedagógico das instituições de ensino. As medidas provisórias são editadas geralmente para atender objetivos 
imediatistas sem serem amplamente discutidas pela sociedade para que sejam aperfeiçoadas. A LDB, por sua vez, trouxe vários benefícios para as IESs públicas e privadas, mas não houve preocupação por parte daqueles que a regulamentaram com as peculiaridades de cada categoria das instituições de ensino.

O terceiro problema macroambiental é a variável demográfica com a explosão da demanda por cursos superiores, justificada pelo crescimento vegetativo da população e pela chegada de novas gerações de faixa etária cada vez menores e quantitativamente maiores que as gerações anteriores. As instituições públicas atenderam a essa demanda com um pequeno aumento de vagas, mas as instituições privadas arcaram com a maior parte da demanda, o que justifica o grande crescimento tanto no número de cursos quanto no número de vagas dessas instituições, mesmo com as restrições impostas pelos órgãos responsáveis pela fiscalização do Ensino Superior no país: CNE (Conselho Nacional de Educação) e CEE (Conselho Estadual de Educação). Além disso, os candidatos que chegam às escolas são cada vez mais jovens e em maior número, o que exige das instituições um cuidado maior quanto a um atendimento pedagógico mais eficiente na área de orientação educacional.

O quarto problema macroambiental são as variáveis socioculturais com a nova geração de alunos da era digital que chegam às IESs com menos hábito de leitura e maior afinidade com os ícones e recursos da multimídia do que com os meios tradicionais de comunicação ainda utilizados pelos docentes como prática pedagógica. A democratização do ensino ampliou o número de vagas na Educação Básica e conseqüentemente na educação superior, mas com uma clientela menos preparada. E as instituições têm o dever de se preparar para atender a esses alunos adequando seu corpo docente e técnicos administrativos para que haja um atendimento mais ágil e eficiente. Quanto ao despreparo desses alunos, é necessário que a instituição lhes dê condições de se engajarem no processo interativo de construção do conhecimento, usando meios adequados, mesmo que seja para suprir alguma deficiência do Ensino Fundamental e Médio.

Educ. e Filos., Uberlândia, v. 20, n. 39, p. 163-185, jan./jun. 2006. 
O quinto são as variáveis tecnológicas trazidas pelo uso de microcomputadores nos laboratórios e em salas de aulas, provocando grande impacto no processo de ensino-aprendizagem. É claro que as técnicas tradicionais de ensino não vão ser descartadas, mas, se existe uma tecnologia mais avançada para se atingir bons resultados na escola, por que não utilizá-las em proveito do aluno, que é o objetivo maior da educação.

E o sexto são as variáveis da economia digital em que o capital humano é mais importante que o capital tradicional. Este novo contexto exige das IESs mais ênfase no gerenciamento do conhecimento e não apenas na administração de dados ou informações; exige, também, a correta compreensão e interpretação das novas gerações que estão chegando, a geração "Internet" ou da era digital, com uma nova cultura, valores e perfil psicológico. Para não se estagnar, a escola tem que estar sempre buscando novos conhecimentos, aperfeiçoando-se e aperfeiçoando seu corpo técnico e docente. Para isso, a pesquisa entra como um meio importante de busca desse conhecimento.

\section{O público e o privado}

Além das variáveis macroambientais que atingem as instituições de ensino causando problemas administrativos e pedagógicos, há um outro problema que parece afetar mais fortemente algumas instituições: a falta de explicitação clara da natureza jurídica das instituições e os problemas advindos de uma conceituação não muito precisa do que é público, privado e estatal e o conseqüente problema da relação entre mantenedoras e mantidas que se estabelece devido à ingerência política não declarada, mas facilmente percebida nas decisões administrativas.

A fim de justificar a afirmação acima, é necessário buscar-se no dicionário a definição de alguns termos:

público. [do lat. Publicu.] Adj. 1. Do, ou relativo, ou pertencente ou destinado ao povo, à coletividade. 2. Relativo ou pertencente ao governo de um país. 3. Que é do uso de

Educ. e Filos., Uberlândia, v. 20, n. 39, p. 163-185, jan./jun. 2006. 
todos; comum. (FERREIRA, 1986, p. 1414).

privado. [Part.de privar.] Adj. 1.Que não é público; particular. (FERREIRA, 1986, p. 1394).

estatal. [do lat.statu, 'estado',+ -al.] Adj.1.Pertencente ou relativo ao Estado. (FERREIRA, 1986, p. 717).

Como pode ser observado, faz-se uma grande confusão com o conceito daquilo que é público, misturando as definições 1 e 2, ou seja, entendendo que tudo que é público, é também pertencente ao governo. Mas isso não é verdade. Nem tudo que é público pertence ao Estado ou ao governo. As instituições de ensino, independente de seu caráter privado ou estatal, deveriam todas elas serem públicas em termos organizacionais, porque seu fim, seu objetivo último é social. Elas deveriam ter como missão "estarem destinadas ao povo, à coletividade", independentemente da sua natureza jurídica de pertencerem ao Estado ou serem privadas.

Segundo a Lei 9.394/96, em seus Artigos 19 e 20, as instituições de ensino podem ser de natureza jurídica diversas.

As instituições de ensino dos diferentes níveis classificam-se nas seguintes categorias administrativas: I- públicas, assim entendidas as criadas ou incorporadas, mantidas e administradas pelo Poder Público; II- privadas, assim entendidas as mantidas e administradas por pessoas físicas ou jurídicas de direito privado. [...] As instituições privadas de ensino se enquadrarão nas seguintes categorias: Iparticulares em sentido estrito, assim entendidas as que são instituídas e mantidas por uma ou mais pessoas físicas ou jurídicas de direito privado que não apresentem as características dos incisos abaixo; II- comunitárias, assim entendidas as que são instituídas por grupos de pessoas físicas ou por uma ou mais pessoas jurídicas, inclusive cooperativas de professores e alunos que incluam na sua entidade mantenedora representantes da comunidade; IIIconfessionais, assim entendidas as que são instituídas por grupos de pessoas físicas ou por uma ou mais pessoas

Educ. e Filos., Uberlândia, v. 20, n. 39, p. 163-185, jan./jun. 2006. 
jurídicas que atendem a orientação confessional e ideologias específicas e ao disposto no inciso anterior; IV- filantrópicas, na forma da lei (LDB, Artigos 19 e 20, p.12).

No chamado "Programa de Publicização" que fazia parte da proposta de Reforma do Estado do então Ministro Bresser Pereira ${ }^{1}$, defendia-se a transformação de entidades estatais de serviço (entre elas as universidades públicas) em "entidades públicas nãoestatais", o que daria às instituições autonomia de gestão de receitas e despesas, porque se tornariam entidades de direito privado, mas com o Estado garantindo a cessão de seus bens e seus funcionários estatutários.

A proposta não foi bem recebida pela comunidade acadêmica que via, por trás dela, a possibilidade do fim da gratuidade do ensino e, conseqüentemente, a privatização do Ensino Superior Público.

A transformação das IFES² em 'organizações sociais' com autonomia plena para gerir e captar seus recursos (diversificação de fontes) expõe a educação superior a um processo de 'privatização' menos explicito do que aquele ocorrido durante a década de 70, mas não menos efetivo. Além do que, a implantação do ensino pago nas instituições federais de ensino superior parece estar no horizonte da Reforma: as aberturas jurídicas estão sendo postas para sua efetiva concretização, se o curso dos eventos continuar sendo comandado pelo governo. A transformação de todas as IFES nesta nova forma jurídica obriga à mudança da natureza do financiamento da educação superior brasileira, o deslocamento do setor público para o setor privado, especialmente, para o setor produtivo. Tal alteração impõe transformações no processo acadêmico-científico desenvolvido nas IES, principalmente nas estatais. O

1 Ministro da Administração e Reforma do Estado no primeiro governo do Presidente Fernando Henrique Cardoso.

2 Instituições Federais de Ensino Superior. 
desenvolvimento da pesquisa e, conseqüentemente, das demais atividades do ensino superior ficaria relativamente subordinado à lógica privada da economia, impondo-se, desta forma, uma perda da capacidade crítica e reflexiva própria da natureza do trabalho acadêmico-científico com profundas conseqüências para a formação dos milhares de estudantes brasileiros (SGUISSARDI, 1997, p. 26).

As instituições de direito privado que mantêm um caráter público não-estatal, ou seja, não visam lucro e toda a renda é destinada aos fins educacionais, poderiam talvez ser incorporadas ao segmento comunitário assim definido e explicitado por Bittar (2000, p. 15 e 16):

Surgidas no bojo da chamada crise de identidade da universidade brasileira, as instituições comunitárias procuraram agregar-se tendo em vista a construção de sua própria identidade. Para tanto, a necessidade de se afastarem do segmento privado empresarial tornou-se um imperativo, visto que este representa objetivos e interesses nem sempre compatíveis com os das comunitárias. Com o intuito de defender as suas próprias reivindicações, especialmente no que diz respeito à relação com os órgãos governamentais educacionais, o segmento comunitário funda a Associação Brasileira das Universidades Comunitárias. A maior bandeira da entidade consiste em disseminar, por meio de seminários e da criação de um jornal, a idéia de que o grupo composto por trinta e duas universidades em todo o Brasil possui uma proposta alternativa de ensino superior: são instituições que nasceram de grupos religiosos ou da própria comunidade, com experiências acumuladas no campo do ensino (infantil, fundamental e médio), "entidades filantrópicas sem fins lucrativos", cujas receitas devem reverter em favor de sua própria finalidade: a educação. Buscando diferenciar-se do chamado ensino privado "empresarial" ou "comercial", os representantes das universidades comunitárias passam a

Educ. e Filos., Uberlândia, v. 20, n. 39, p. 163-185, jan./jun. 2006. 
denominar suas instituições como "públicas não-estatais", indicando que este seria o aspecto inovador de suas propostas: pelo fato de prestarem um serviço público - caracterizado pelos trabalhos sociais desenvolvidos junto às populações de baixa renda - buscam aproximar-se do setor público estatal, distanciando-se do segmento estritamente particular.

O lucro advindo dessas organizações não é apenas financeiro e sim político e social. Mas, um dos problemas mais sérios da administração dessas instituições é o uso do nome da organização para fins políticos-partidários como distribuição de cargos e para aumentar o prestígio político dos gestores ligados à mantenedora. Os critérios que definem as decisões administrativas deixam de ser técnicos e passam a ser político-privados e quem perde é o fim último da instituição: o pedagógico. A organização é de caráter público, mas sua gestão é assumida com característica individualista e privada: as decisões não são compartilhadas.

Em decorrência da ingerência político-privada há a falta de clareza dos objetivos e da missão da instituição; o papel dos diretores das faculdades, coordenadores de cursos e chefes de departamentos não são bem definidos, levando cada um a trabalhar para um lado determinado, sem autonomia na tomada de decisões, já que dependem sempre da aprovação de recursos que não são definidos no plano de desenvolvimento institucional. Falta apoio ao docente e ao discente que teoricamente seriam a mola propulsora de toda a organização.

É necessário repensar toda a estrutura organizacional das instituições e principalmente definir claramente as funções, descrevendo cada cargo e equipe de trabalho, dando maior autonomia para as decisões colegiadas e exigindo da mantenedora maior transparência na administração dos recursos.

\section{Gestão e qualidade na educação}

Dentre as várias tendências de uso das recentes teorias da Administração, pode-se escolher a da Qualidade Total. Incorporada 
aos vários modelos de gestão empresarial, já é inclusive adotada com facilidade e sem criticidade por alguns educadores. A Qualidade Total fundamenta uma das eras do desenvolvimento da teoria administrativo empresarial (Era da Qualidade) e é condição sine qua non das três formas de administração que acreditamos estarem mais afeitas como fundamentação para as mudanças que precisam ocorrer na administração escolar: Administração Participativa, Administração Holística e, principalmente, Administração Estratégica.

A análise da Qualidade Total na Educação se apresenta como excelente instrumento para se compreender as afinidades e as divergências entre a Administração Empresarial e a Escolar. O Controle da Qualidade Total é um movimento que se inicia na década de 30 nos Estados Unidos, mas que vai realmente se desenvolver no Japão, após a Segunda Guerra Mundial. A teoria de Deming ${ }^{3}$ encontrou terreno fértil no Japão devastado pela guerra e fez com que os produtos industrializados japoneses se tornassem altamente competitivos no mercado internacional, colocando o Japão numa posição privilegiada entre as nações mais ricas do mundo. O fenômeno japonês fez escola e passou a ser estudado e copiado por outros países, inclusive pelos Estados Unidos.

No Brasil, a Qualidade Total aplicada à empresa chegou por meio de um programa governamental na era Collor.

O conceito de Qualidade Total desenvolvido pelos norteamericanos na década de 30 e aperfeiçoado pelos japoneses no período pós-guerra começa a criar raízes em solo brasileiro, influenciado pelas mudanças políticas e econômicas ocorridas em vários países do mundo. Em 7 de novembro de 1990, o Presidente Collor lançou o Programa Brasileiro de Qualidade e Produtividade (PBQP) e instituiu 1991 como o Ano Nacional da Qualidade e Produtividade, prometendo

3 W. Edwards Deming - idealizador do Método Deming, baseado em 14 pontos que aplicados na empresa levariam-na ao sucesso.

Educ. e Filos., Uberlândia, v. 20, n. 39, p. 163-185, jan./jun. 2006. 
"um choque de eficiência e de qualidade em todo o ambiente econômico e social". A partir daí, o empresariado brasileiro, de modo especial, e setores de prestação de serviços se conscientizaram de que a saída para acompanhar o desenvolvimento do primeiro mundo era investir em qualidade. Começou, então, a febre da qualidade, que tem invadido empresas, indústrias, áreas de saúde, setor educacional, etc., nos quais só se fala em qualidade total. $\mathrm{O}$ "vírus" da qualidade invadiu a empresa brasileira e se espalhou pelos demais setores de atividade (SILVA, 1995, p. 32-3).

Em uma análise mais cuidadosa, constata-se que a Qualidade Total tem suas raízes no contexto do neoliberalismo ${ }^{4}$, trazendo consigo suas marcas e tendências. Em educação, as idéias que subjazem ao conceito de Qualidade Total do neoliberalismo são muito parecidas com o tecnicismo e o pragmatismo da década de 60 .

São muitas as analogias que podem ser estabelecidas entre o tecnicismo e o neoliberalismo: articulação da escola com o setor produtivo; valorização da Teoria do Capital Humano; ênfase na burocratização, na tecnocracia e na quantificação estatística; fragilização e sucateamento dos conteúdos escolares; adoção de um modelo de avaliação objetivo e fincado em aspectos quantitativos e pontuais; priorização de uma visão acrítica e despolitizada da educação; crescimento da privatização do ensino; desvalorização e expropriação do saber do professor. Enfim, pode-se afirmar que o neoliberalismo se constitui, de fato, como um neotecnicismo (OLIVEIRA, 1998, p. 112).

Na educação, a chamada Pedagogia da Qualidade teve como sua grande defensora e divulgadora a administradora Cosete

4 O neoliberalismo se caracteriza por pregar que o Estado intervenha o mínimo na economia, mantenha a regulamentação das atividades econômicas privadas e deixe agir livremente os mecanismos do mercado. (GENTILI, 1999, p. 26). 
Ramos $^{5}$. Segundo ela, "esta proposta traz consigo uma estratégia inovadora de transformação de baixo para cima, de cada escola, de cada instituição de ensino para a melhoria global do sistema educativo nacional." (RAMOS, 1992, p. 87, grifado no original).

O programa de qualidade para a escola consiste na aplicação do Método Deming de Administração na gestão de instituições de ensino. Em primeiro lugar, é necessária a adesão de todos; em seguida, todos devem ser treinados para agir de forma padronizada ${ }^{6}$.

Para que se obtenham os resultados esperados é preciso que o indivíduo aprenda a ter iniciativa, a ser capaz de: dominar as estratégias e técnicas de gerenciamento da qualidade, conhecer suas tarefas e entender suas imbricações nos processos de trabalho antecedentes e subseqüentes. Visando a introjeção desses conhecimentos e das necessárias normas e padrões, procede-se a um treinamento intensivo e em cascata, de cunho notoriamente pragmático e que se constitui como autêntico mecanismo de disciplinamento e de modelamento dos trabalhadores (OLIVEIRA, 1998, p. 64).

Mas, o que é realmente qualidade?

Qualidade. [Do lat.qualitate.] S.f. 1. Propriedade, atributo ou condição das coisas ou das pessoas capaz de distingui-las das outras e de lhes determinar a natureza. 2. Numa escala de valores, qualidade (1) que permite avaliar e, conseqüentemente, aprovar, aceitar ou recusar, qualquer coisa (FERREIRA, 1986, p.1424).

5 Coordenadora adjunta do Núcleo Central de Qualidade e Produtividade subordinado ao Ministério da Educação.

6 "A padronização é um elemento fundamental no controle da qualidade. Tratase de uma estratégia de cunho taylorista que foi resgatada. Pela padronização consegue-se manter a empresa sob controle, ou melhor, ter o trabalho sob controle e vigilância, de uma forma sutil e extremamente eficiente, pois, padronizandose as rotinas, exerce-se domínio sobre o trabalhador " (OLIVEIRA, 1998, p. 66).

Educ. e Filos., Uberlândia, v. 20, n. 39, p. 163-185, jan./jun. 2006. 
No entender dos defensores da Qualidade Total, o CQT Controle de Qualidade Total — parte do reconhecimento das necessidades das pessoas e estabelece padrões para o atendimento dessas necessidades. Objetiva manter esses padrões e melhorá-los continuamente a partir de uma visão estratégica e com abordagem humanista. Seu conteúdo se resume na "satisfação do cliente".

Endeusada por uns e execrada por outros, é uma técnica aplicada à administração que tem provado ter seus méritos, mas deve ser repensada em alguns pontos, sobretudo quando implantada em uma instituição de ensino.

Dentro dessa visão, entende-se que a educação busca hoje um novo paradigma e é possível que este seja o da Pedagogia da Qualidade. A educação não pode ficar alheia ao que acontece nos setores da atividade humana. O importante é pensar que essa qualidade não pode ser tratada sob os mesmos parâmetros da qualidade empresarial. Afinal, o aluno é aluno em toda a sua potencialidade, é alguém que aprende como aprender, quer construir seu saber, quer direcionar seu projeto de vida. Ele não é cliente da escola, mas, sim, parte dela. Isso dá uma nova dimensão ao problema (SILVA, 1995, p.29).

Qualidade, na verdade, é condição sine qua non em qualquer instituição, seja ela uma empresa ou uma escola. Muitas das estratégias usadas na implantação, controle e avaliação do CQT encontram-se na organização e gestão das IES. O plano de desenvolvimento institucional, os projetos pedagógicos dos diferentes cursos e a própria avaliação institucional são muito semelhantes às estratégias aplicadas durante todo o processo do CQT. Os termos planejamento, missão e objetivos são comumente usados por ambos.

Então, o que é criticado no CQT? Todos os recursos aplicados à administração têm como objetivo principal aumentar a produtividade, diminuindo os custos de produção. Em uma IES isso não é possível porque sua produtividade não é mensurável e não possui relação direta e automática com os meios e custos. O 
conhecimento, objetivo primeiro da educação, não pode ser medido ou tratado da mesma forma que se mede a produção de carros. $\mathrm{O}$ processo de construção do conhecimento não pode ser visto como um produto pronto e acabado a ser adquirido. $\mathrm{O}$ conhecimento não pode ser maquiado para ser vendido, com se faz com o produto; portanto, a IES não tem produto manipulável. O produto da escola não é nem o serviço ao aluno, mas o conhecimento, e conhecimento não se torna mercadoria e não tem preço. O preço é dado ao serviço.

A investida para se implantar os critérios empresariais de eficiência, de "qualidade total", de competitividade em áreas incompatíveis com os mesmos, como educação e saúde, desenvolve-se hoje dentro do setor "público". O que é, sem dúvida, profundamente problemática é a pressão da perspectiva neoconservadora para que a escola pública e a Universidade em particular e a área da saúde se estruturem e sejam avaliadas dentro dos parâmetros da produtividade e eficiência empresarial (GENTILI, 1994, p. 49).

Cosete Ramos (1992, p. 17) afirma que o aluno é um cliente: "Uma Escola envolvida na Filosofia da Qualidade torna claro que trabalha em função do seu cliente mais destacado - o aluno -, [...]." (grifado no original). De fato, o aluno se assemelha ao cliente na escola quando entra na secretaria, na tesouraria ou na biblioteca. Nesses setores, ele deve receber o mesmo tratamento que recebe o cliente em uma loja ou supermercado; o mesmo tratamento que qualquer consumidor recebe daquele que produz ou comercializa um produto ou presta um serviço. Porém, a sua relação com a instituição em seu espaço específico, na sala de aula, é diferente, porque se constrói na relação pedagógica professor/ aluno, construindo e produzindo conhecimento, em um constante vir a ser. O aluno não é cliente para o professor, é co-participante do processo educacional que, por sua vez, é conduzido pelo professor. A escola pode e deve buscar a excelência no processo educacional oferecendo condições adequadas para que a construção do conhecimento se concretize, investindo em infra-

Educ. e Filos., Uberlândia, v. 20, n. 39, p. 163-185, jan./jun. 2006. 
estrutura, em laboratórios, em um bom plano de cargos e salários para o professor e o pessoal técnico-administrativo. Aliás, nenhuma empresa trabalha sem um plano de cargos e salários. É importante, também, que ela invista em avaliação (outra ferramenta da Qualidade Total amplamente utilizada na empresa) — avaliação interna e avaliação externa — pois é apoiado nos dados da avaliação que se pode aplicar estratégias administrativas e pedagógicas que conduzam a instituição à excelência.

As IESs devem ser um lugar onde diferentes formas de pensar, diferentes ideologias convivam e se conflituam para que novos conhecimentos sejam produzidos em torno do debate entre várias idéias. Logo, não é um lugar onde as pessoas devem falar o mesmo "idioma", onde todos devem possuir o mesmo conceito sobre a mesma terminologia para que haja consenso e harmonia em torno das questões relativas à gerência da qualidade. A oposição, o debate, os diferentes pensamentos ajudam na construção do conhecimento dentro da escola e fazem parte do processo pedagógico. Entretanto, "nessa idéia de totalidade (Qualidade Total) não sobra espaço para a contradição" (FIDALGO, 1994, p. 21).

O CQT representa continuidade de um movimento de idéias gerenciais desenvolvidas desde a Escola de Relações Humanas, iniciada nos anos 30. É um grande avanço em relação aos processos taylorista e fordista de administração. Mas como todo e qualquer recurso aplicado à empresa, tenta controlar o processo de trabalho não só por intermédio da tecnologia e das inovações organizacionais, bem como tentando dominar fatores subjetivos como envolvimento pessoal, colaboração voluntária, treinamento e formação contínuos. O próprio discurso de Cosete Ramos sobre qualidade na educação é doutrinário, condicionador e dogmático.

Os dois livros que escrevemos sobre Qualidade Total na Educação refletem exatamente esta proposta: no primeiro buscou-se conscientizar e motivar as pessoas para a Qualidade e, agora, nesta obra, pretende-se oferecer as condições técnicas necessárias à operacionalização da Qualidade na Escola (RAMOS, 1994, p. 11). 
Esse discurso doutrinário é criticado por muitos autores, entre eles, a autora de Escola ou empresa, Cosete Ramos:

[...] os teóricos do "CQT" consideram que os problemas das empresas (e, por extensão, os da escola) podem ser resolvidos apenas com a boa vontade, o envolvimento de todos, com o uso de um gerenciamento eficiente e com o emprego de técnicas de controle e avaliação. Assim, o "CQT" caracterizase por seu evidente sentido microinstitucional, baseado na crença de que, com o uso de estratégias de cunho participativo, a escola se transforma, envolvida por otimismo e por uma fé contagiante na função redentora da qualidade (OLIVEIRA, 1998, p. 76).

Alguns benefícios podem ser percebidos quando é implantado o CQT: a padronização dos serviços de secretaria e biblioteca; a organização, adequação e limpeza do espaço físico; o gerenciamento e a administração da escola e a avaliação de cada parte e do todo. Ou seja, a racionalização dos meios para se atingir o fim.

No entanto, o objetivo final da escola escapa e ultrapassa os meios organizacionais que ajudam, ao pavimentar os caminhos, mas prejudicam ao serem criadores de cerciamentos e limitações à aprendizagem que se move em outros espaços.

\section{Conclusões}

Conclusivamente, é possível afirmar que as estratégias de gestão aplicadas à empresa podem e devem ser assumidas pelas IESs, desde que respeitadas as diferenças entre os fins e a natureza da produção de uma e outra instituição.

Qualidade é "algo que deve ser construído" a partir de um diagnóstico do estado atual, do planejamento do nível da qualidade que se pretende e de um projeto de programa de desenvolvimento e aprimoramento. Qualidade é um objetivo

Educ. e Filos., Uberlândia, v. 20, n. 39, p. 163-185, jan./jun. 2006. 
estratégico. Assim, todo o futuro da qualidade será, então, de gestão estratégica para manter e aprimorar, constantemente, os níveis da qualidade de vida para as pessoas, estejam onde estiverem (SILVA, 1995, p. 36).

Logo, tanto a Qualidade Total, quanto as modernas estratégias de gestão empresarial podem ser benéficas para a escola, desde que analisadas criticamente e levando-se em consideração as especificidades das instituições de ensino. Em primeiro lugar, o aspecto mais importante: aluno não é cliente, mas parceiro na produção do conhecimento; e conhecimento não é produto comercial, porque não já está dado e não pode ser apropriado ou comprado. Ele é adquirido nas relações epistemológicas de sua construção, estabelecidas entre professor e aluno na sala de aula. Em segundo lugar, os aspectos administrativos burocráticos e serviços são atividades-meio da instituição, utilizadas para que ela possa atingir seus objetivos-fins que são as atividades pedagógicas, as prioritárias dentro da instituição de ensino. Por último, é necessário que a escola se aposse das ferramentas administrativas da empresa, modernize seu processo gestionário, otimizando suas ações, agilizando suas decisões, mas com criticidade e sem perder de vista as peculiaridades do desenvolvimento do processo pedagógico, lembrando sempre que as relações administrativas são meios e as relações pedagógicas são fins e o administrativo está a serviço do pedagógico.

\section{Referências}

BARROS, Davi Ferreira \& SILVA, Rinalva Cassiano. Entre a autonomia e a competência: tópicos em administração universitária. Piracicaba: Unimep, 1998.

BITTAR, Mariluce. O ensino superior privado no Brasil e a formação do segmento das universidades comunitárias. Caxambu: CD-Rom Anped / $23^{\circ}$ Reunião Anual. GT 11. Política de Educação Superior, 2000. 
BRASIL/MEC. Lei de Diretrizes e Bases da Educação Brasileira. LDB 9394/96. Belo Horizonte: SINPRO - MG, 1997.

ESTRELA, Albano. Pedagogia, ciência da educação? Portugal: Porto, 1992.

FÉLIX, Maria de Fátima Costa. Administração escolar. São Paulo: Cortez/Autores Associados, 1984.

FERREIRA, Aurélio Buarque de Holanda. Novo dicionário Aurélio da Lingua Portuguesa. Rio de Janeiro: Nova Fronteira, 1986.

FIDALGO, Fernando S. \& MACHADO, Lucília R. S. (Org). Controle da qualidade total: uma nova pedagogia do capital. Belo Horizonte: Movimento de cultura marxista, 1994.

GENTILI, Pablo A. A. \& SILVA, Tomaz Tadeu da (Org.). Neoliberalismo, qualidade total e educação. Petrópolis: Vozes, 1999.

LIBÂNEO, José Carlos. Organização e gestão da escola. Goiânia, Editora do Autor, 2000.

MARCOVITCH, Jacques. A universidade impossível. São Paulo: Futura, 1998.

OLIVEIRA, Maria Auxiliadora Monteiro. Escola ou empresa? Petrópolis: Vozes, 1998.

PARO, Vitor Henrique. Administração crítica. São Paulo: Cortez/ Autores Associados, 1986.

RAMOS, Cosete. Excelência na educação: a escola de Qualidade Total. Rio de Janeiro: Qualitymark, 1992. 1994. Pedagogia da qualidade total. Rio de Janeiro, Qualitymark, 
REZENDE, Antonio M. O saber e o poder na universidade. São Paulo: Cortez/Autores Associados, 1987.

SENGE, Peter M. A quinta disciplina. São Paulo: Best Seller, 1990.

SGUISSARDI, Valdemar. Avaliação universitária em questão. Campinas: Autores Associados, 1997.

SILVA, Maria Vieira. Trabalho docente e gestão escolar: formação, deformação e transformação do educador. 1995. Dissertação (Mestrado em Educação), Universidade Federal de Uberlândia, Uberlândia, 1995.

TAKESHY, Tachizawa. \& ANDRADE, Rui Otávio B. Gestão de instituições de ensino. Rio de Janeiro: FGV, 1999.

Data de Registro 01/09/05

Data de Aceite 27/09/05 